\title{
FAKTOR-FAKTOR YANG MEMPENGARUHI KINERJA PEMASARAN PADA PT PRIMA UFUK SEMESTA (Studi Empiris Pada Outlet Rekanan PT. Prima Ufuk Semesta di Wilayah JABODETABEK)
}

\author{
Dede Solihin, S.E., M.M. \\ Tenaga Pengajar Fakultas Ekonomi Universitas Pamulang \\ Email : dosen02447@unpam.ac.id
}

\begin{abstract}
ABSTRAK
Penelitian ini bermaksud untuk mengetahui pengaruh kemampuan tenaga penjualan, strategi pelayanan outlet dan hubungan dengan outlet terhadap kinerja pemasaran Pada Outlet Rekanan PT. Prima Ufuk Semesta di Wilayah Jabodetabek.

Penelitian ini bersifatkausalitas dengan pendekatan kuantitatif. Populasi dalam penelitian ini adalah seluruh outlet rekanan PT. Prima Ufuk Semesta di wilayah Jabodetabek, sedangkan sampel yang digunakan dalam penelitian ini sebanyak 152outlet. Teknik pengumpulan data dengan cara kuesioner, dan Teknik analisis data yang digunakan dalam penelitian ini menggunakanStructural Equation Modeling (SEM).

Hasil penelitian memberikan bukti empiris bahwa kemampuan tenaga penjualan berpengaruh positif dan signifikan terhadap kinerja pemasaran, dengan koefisien jalur sebesar 0,260 dan nilai $\mathrm{P}=0,006$, strategi pelayanan outlet berpengaruh positif dan signifikan terhadap kinerja pemasaran dengan koefisien jalur sebesar 0,210 dan nilai $\mathrm{P}=0,030$. Hubungan dengan outlet berpengaruh positif dan signifikan terhadap kinerja pemasaran dengan koefisien jalur sebesar 0,262 dan nilai $\mathrm{P}=0,006$.
\end{abstract}

Kata Kunci : Kemampuan Tenaga Penjualan, Strategi Pelayanan Outlet, Hubungan Dengan Outlet, Kinerja Pemasaran.

\section{ABSTRACT}

This study intends to determine the effect of the ability of the sales force, outlet service strategies and relationships with outlets on marketing performance at PT Partner Outlets. Prima Ufuk Universe in the Greater Jakarta Area.

This research is causality with a quantitative approach. The population in this study were all partner outlets of PT. Prima Ufuk Semesta in the Greater Jakarta area, while the samples used in this study were 152 outlets. Data collection techniques by questionnaire, and data analysis techniques used in this study using Structural Equation Modeling (SEM).

The results provide empirical evidence that the ability of the sales force has a positive and significant effect on marketing performance, with a path coefficient of 0.260 and a value of $P=0.006$, an outlet service strategy has a positive and significant effect on marketing performance with a path coefficient of 0.210 and a value of $P=0.030$. The relationship with the outlet has a positive and significant effect on marketing performance with a path coefficient of 0.262 and a value of $P$ $=0.006$. 
Keywords: Sales Force Ability, Outlet Service Strategy, Outlet Relations, Marketing Performance.

\section{PENDAHULUAN}

\section{A. Latar Belakaang}

Persaingan dalam penerbitan buku di zaman era teknologi dan informasi yang semakin ketat ini menyebabkan banyaknya perusahaan penerbitan maupun distributor buku harus bekerja keras dalam mempertahankan eksistensi kelangsungan hidup perusahaan. Rendahnya minat baca masyarakat serta maraknya buku-buku bajakan turut mempengaruhi kinerja pemasaran. Ditambah lagi munculnya e-book yang mempermudah pelanggan dalam membaca dengan hanya mendownload tanpa harus membeli juga menambah persaingan yang terjadi.

Untuk meningkatkan kinerja pemasaran distributor terhadap outlet maka perusahaan perlu memperhatikan aspek-aspek yang mempengaruhinya seperti kemampuan tenaga penjualan dalam berkomunikasi terhadap outlet, menetapkan strategi pelayanan yang berkualitas kepada outlet rekanan, serta bagaimana menjaga hubungan yang baik dengan outlet agar dapat menciptakan kepercayaan yang baik antara distributor dengan outlet rekanan.

PT. Prima Ufuk Semesta adalah perusahaan distribusi buku kelompok Zaytuna Ufuk Publishing yang pendistribusian bukunya hampir menjangkau semua toko buku di wilayah Indonesia, mulai dari Nanggaro Aceh Darussalam sampai Papua. Berbagai jenis buku bacaan ditawarkan kepada pembaca mulai dari buku politik, buku hukum, buku sosial budaya, buku psikologi, buku anak, buku agama, dan buku lainnya yang tentunya sangat berkualitas dan sangat bermanfaat bagi pembacanya.

Tabel 1 Data Penjualan PT. Prima Ufuk Semesta di Wilayah JABODETABEK

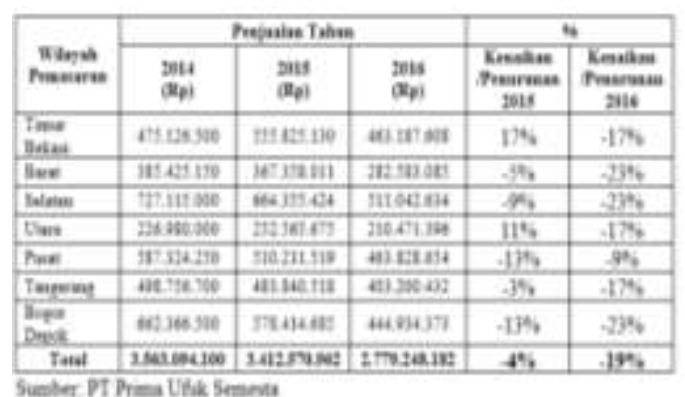

Dari data penjualan tersebut terlihat jelas bahwa volume penjualan pada PT. Prima Ufuk Semesta cenderung menurun pada periode 2 tahun. Didapati bahwa volume penjualan pada tahun 2015 turun sebesar 4\% jika dibandingkan dengan tahun 2014, sedangkan tahun 2016 volume penjualan juga menurun sebesar $19 \%$ jika dibandingkan dengan tahun 2015.

Berdasarkan hasil observasi yang penulis lakukan bahwa penurunan penjualan ini disebabkan oleh beberapa hal diantaranya: didapati adanya beberapa tenaga penjual yang kurang memiliki inisiatif dalam hal membuat laporan dan pemesanan buku-buku yang kondisi stoknya habis, tenaga penjual lebih menunggu pesanan dari pihak toko dibandingkan dengan membuat reapeat order sendiri sehingga 
mengakibatkan banyak stok buku best seller menjadi kosong. Serta lamanya proses cetak ulang buku Best Seller mempengaruhi penjualan yang menurun.

Dukungan layanan juga menjadi faktor yang sering dikeluhkan oleh outlet. Tenaga pemasar dirasa kurang dalam memberikan pelayanan yang maksimal, misalnya dalam hal waktu untuk proses pemesanan produk yang terkesan lama contohnya buku yang seharusnya datang dalam jangka waktu 7 hari kenyataannya datang di hari ke 15 . Hal ini membuat beberapa outlet memiliki hubungan yang kurang harmonis dengan tenaga pemasar pada PT Prima Ufuk Semesta. Selain hal tersebut juga adanya pengaduan dari pihak outlet bahwa tenaga penjual jarang sekali melakukan kunjungan ke toko, kurangnya komunikasi antara tenaga penjual dengan pihak toko membuat komunikasi menjadi terhambat sehingga proses penyampaian informasi mengenai ketersediaan buku-buku yang dibutuhkan oleh pihak toko tidak tersampaikan. Fenomena lain yang penulis temukan yaitu banyaknya buku-buku returan yang jarang di kroscek oleh tenaga penjualan padahal kroscek buku returan merupakan salah satu tugas yang harus dijalankan oleh tenaga penjual sehingga menyebabkan hubungan yang kurang baik dengan pihak toko.

\section{LANDASAN TEORI}

\section{A. Kemampuan Tenaga Penjualan}

\begin{tabular}{lcr}
\multicolumn{2}{c}{ Ferdinand } & $(2004: 56)$ \\
memberikan & definisi & bahwa \\
"kemampuan & tenaga & penjualan
\end{tabular}

selalu dapat dipandang sebagai hasil dari dijalankannya sebuah peran stratejik tertentu, yang bagi seorang tenaga penjualan, kinerja itu dihasilkan sebagai akibat dari keagresifan tenaga penjualan mendekati dan melayani dengan baik pelanggannya". Challagalla dan Shervani (2006:35) menyatakan bahwa "kemampuan tenaga penjualan merupakan suatu tingkat dimana seorang tenaga penjualan dapat mencapai target penjualan yang telah ditetapkan oleh manajer penjualan terhadap dirinya".

\section{B. Strategi Pelayanan Outlet}

Menurut Albrecht dan Zemke (1985) "strategi pelayanan outlet adalah suatu strategi untuk memberikan layanan dengan mutu yang sebaik mungkin kepada para pelanggan". Menurut Arif (2004:58) "strategi pelayanan outlet merupakan upaya dari manajemen untuk memaksimalkan pemasaran perusahaan dengan cara mengatur saluran distribusinya". "Efektivitas keputusan manajemen atas pelayanan outlet akan sangat tergantung dari ketepatan kunjungan (call), sistem pembayaran penjualan (term of payment) yang tepat, dan kebijakan retur yang dipakai”, (Arif, 2004:58).

\section{Hubungan Dengan Outlet}

Day (2000:17) mengemukakan bahwa "hubungan dengan outlet dapat dipandang sebagai bentuk kerjasama yang terjalin antara perusahaan dengan outlet". Demi memperoleh tujuan peningkatan penjualan maka distributor harus selalu dapat mencocokkan kualitas untuk meningkatkan hubungan outlet dengan distributor. Komunikasi antara distributor dan tenaga 
penjualan adalah jantung dari koordinasi kualitas. Karena komunikasi ini adalah integrasi terbaik dari kegiatan distribusi antara distributor dan tempat penjualan dalam hal ini toko atau outlet. Dengan mengintegrasikan kegiatan distribusi yang baik dan dapat dirasakan pelanggan, keunggulan ini diharapkan, dan kontrol intensitas komunikasi memenuhi harapan pasar outlet. Hubungan yang baik dengan outlet akan memberikan keuntungan terutama kinerja pemasaran.

\section{Kinerja Pemasaran}

$$
\text { Menurut Gao }
$$
"kinerja pemasaran merupakan proses multidimensional yang mencakup tiga dimensi efektivitas, efisiensi dan kemampuan beradaptasi; efektivitas dan efisiensi dan aktivitas pemasaran organisasi terkait dengan tujuan terkait pasar, seperti pendapatan, pertumbuhan, dan pangsa pasar".Sampurno (2010:248) menjelaskan bahwa "kinerja pemasaran adalah akumulasi hasil akhir dari seluruh aktivitas dan proses kerja dari perusahaan atau suatu tampilan keadaan secara utuh atas perusahaan selama periode waktu tertentu, yang merupakan hasil atau prestasi yang dipengaruhi oleh kegiatan operasional perusahaan dalam memanfaatkan sumbersumber daya yang dimiliki".

\section{E. Kerangka Berfikir}

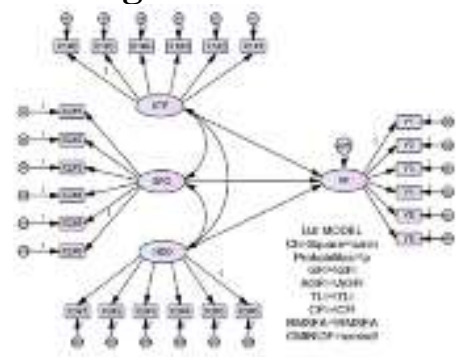

Gambar 1 Kerangka Berfikir

\section{METODE PENELITIAN}

Penelitian ini termasuk dalam tipe penelitian kausalitas yaitu "untuk mengidentifikasi hubungan sebab dan akibat antar variabel dan peneliti mencari tipe sesungguhnya dari fakta untuk membantu memahami dan memprediksi hubungan kemudian dikembangkan suatu bentuk model penelitian yang bertujuan untuk menjelaskan hubungan antar variabel sekaligus membuat suatu implikasi yang dapat digunakan untuk peramalan atau prediksi". (Ferdinand, 2006:78).

Dalam penelitian populasinya adalah seluruh outlet rekanan pada PT Prima Ufuk Semesta yang berjumlah sebanyak 245 outlet di area Jabodetabek. Sementara sampel yang digunakan yaitu sebagai berikut:

Tabel 2 Pengambilan Sampel Penelitian

\begin{tabular}{|c|c|c|c|c|}
\hline $\mathrm{N}_{0}$ & WIlayah & $\begin{array}{c}\text { Jumbh } \\
\text { Otlet }\end{array}$ & Perhitungan & $\begin{array}{l}\text { Jumlah } \\
\text { Sampel }\end{array}$ \\
\hline 1 & Timus - Belasi & 37 & $37245 \times 152=229$ & 23 \\
\hline 2 & Barat & 30 & $30245 \times 152=18,61$ & 18 \\
\hline 3 & Selatm & 38 & $3824 \times 152=235$ & 23 \\
\hline 4 & Ttara & 32 & $32245 \times 152=19,8$ & 20 \\
\hline 5 & Puset & 31 & $5124 \times 152=31,64$ & 32 \\
\hline 6 & Tangerang & 22 & $2224 \times 152=13,65$ & 14 \\
\hline 7 & Bogor - Depolk & 35 & $3524 \times 152=21,7$ & 22 \\
\hline & TOTAL & 245 & Sampel & 152 \\
\hline
\end{tabular}

Metode analisis data yang digunakan dalam penelitian ini adalah model kausal atau pengaruh-hubungan. Alat analisis yang digunakan dalam pemrosesan data untuk menguji hipotesis yang diajukan adalah dengan menggunakan SEM (model persamaan struktural) yang didukung oleh program AMOS (Moment Structure Analysis) versi 22.

IV. HASIL PENELITIAN

\section{A. Pengujian Model}

Analisis SEM digunakan untuk menentukan hubungan struktural antara variabel yang 
diteliti. Hubungan struktural yang muncul antara variabel dapat diuji agar sesuai dengan goodness fit. L model yang diterapkan oleh penulis dengan menggunakan program model persamaan struktural AMOS 22.Hasil uji model dalam penelitian ini menunjukkan bahwa model ini dapat diadopsi sesuai dengan beberapa kriteria kelayakan yang ditunjukkan pada Tabel 3.

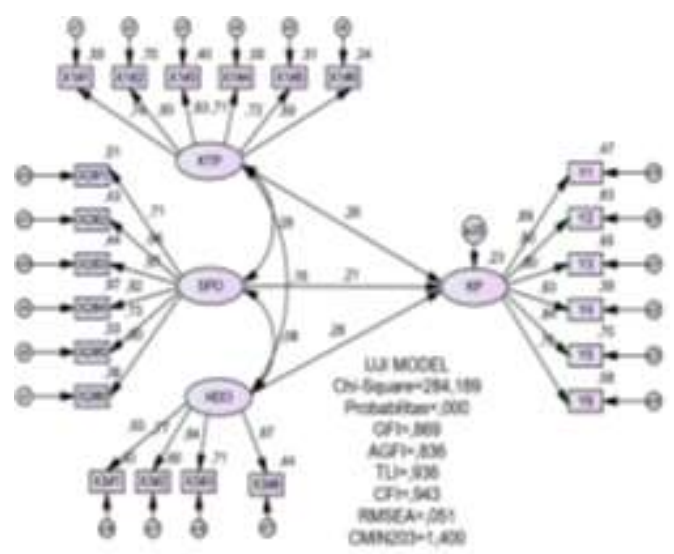

\section{Gambar 2 Full Model Structural Equation Modelling}

Tabel 3Uji Model Goodness of fit

\begin{tabular}{|c|c|c|c|}
\hline Gooders of hadr & Corth Vhe & Had Wodel & Ketenagan \\
\hline Ceserge. & Dimialed DFys $=32,39$ & 24199 & Jergalf \\
\hline GI] & $>198$ & Q1SS & Jogiaif \\
\hline$A C E I$ & $>090$ & 01136 & Hoginalf \\
\hline acide & $<2$ & 140 & Goodt \\
\hline III & 209 & 096 & Goodft \\
\hline CF & $>\sin$ & 393 & Goodf th \\
\hline Powatily & $>016$ & 000 & J brialf \\
\hline RVSEA & $<008$ & 005 & Goif \\
\hline
\end{tabular}

\section{B. Pengujian Hipotesis Kausalitas}

Berdasarkan pada gambar 2 dan tabel 3 tersebut maka langkah selanjutnya adalah dengan mengevaluasi hasil SEM dan tes hipotesis akan dilakukan. Tiga hipotesis yang diajukan dalam penelitian ini diuji dengan menganalisis nilai hubungan kritis (CR) dan probabilitas sebab-akibat yang dapat dilihat pada tabel 4 berikut ini:

\section{Tabel 4Pengujian Hipotesis}

\begin{tabular}{|c|c|c|c|c|c|c|c|}
\hline & & & Eitanatr & SE. & $\mathrm{CR}$ & $P$ & Lubel \\
\hline KF & $c$ & KTP & 222 & 061 & 2.730 & .006 & par_to \\
\hline $\mathrm{KP}$ & 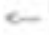 & IEDo & 246 & 089 & 2,797 & 006 & $p a z=30$ \\
\hline KP & 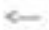 & SPO & 223 & .103 & 2.171 & .030 & $\operatorname{par} 21$ \\
\hline $\mathrm{X}:=2$ & c- & KTP & 1.212 & 128 & 9.456 & $\cdots$ & $p=1$ \\
\hline$X \mid=3$ & $5-$ & $\mathrm{KI?}$ & 940 & 128 & 7,593 & $\cdots$ & pus 2 \\
\hline$X_{1}=4$ & 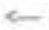 & $\mathrm{KTP}$ & .962 & 117 & 1.221 & $\cdots$ & par 3 \\
\hline$X:=5$ & 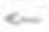 & KT? & 1.066 & 125 & 3.305 & ... & Far 4 \\
\hline$x \leq 25$ & 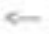 & SPO & 1.394 & 196 & 6.505 & $\ldots$ & $p=3$ \\
\hline$x_{2}=4$ & 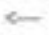 & SPOO & 1.715 & 231 & 7,410 & $*$ & $p_{-6}$ \\
\hline X203 & $<$ & SPO & 1.346 & 212 & 0.327 & $\cdots$ & $p=7$ \\
\hline $\mathrm{X} 2 \mathrm{v}_{2}$ & - & spo & 1.299 & 201 & 6.249 & $* *$ & pars \\
\hline$x 3=6$ & $c$ & HDO & 1.000 & & & & \\
\hline$X 3$ s] & 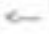 & भก० & 1.198 & .144 & 7,776 & $\cdots$ & par_g \\
\hline$x 3=2$ & a & HDO & 1.127 & .146 & 7,709 & 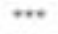 & par_10 \\
\hline$X 3=1$ & $c$ & FDO & 981 & 145 & 6,747 & $\cdots$ & $\mathrm{par}_{2} 11$ \\
\hline$v_{2}$ & $<-$ & KP & 1.252 & 143 & $8 \pi$ & *.. & pas_12 \\
\hline Y3 & 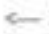 & KP & 1,304 & 138 & 8.735 & $\cdots$ & par 13 \\
\hline$\gamma_{4}$ & $c$ & KR & 838 & 117 & 3,153 & $\cdots$ & par 14 \\
\hline Y5 & 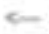 & KPP & 1,253 & 196 & 0,201 & w. & par_15 \\
\hline$x=1$ & - & s20 & 1,446 & 223 & 6,482 & $w$ & pur_22 \\
\hline$X 2=0$ & 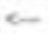 & 590 & 1.060 & & & & \\
\hline$x=1$ & 5 & KI? & 1.000 & & & & \\
\hline$x !=6$ & $<$ & $\mathrm{kTP}$ & in & .118 & 6.912 & $\omega *$ & $p a t 23$ \\
\hline Yo & 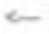 & KP & 1,260 & .141 & 8.54 & $*$ & $\operatorname{par} 24$ \\
\hline $\mathrm{r}$ & $<$ & KSP & 1.000 & & & & \\
\hline
\end{tabular}

\section{Pengujian Hipotesis 1}

Berdasarkan pada tabel 4 diketahui bahwa variabel tenaga penjualan memiliki nilai probabilitas $0,006<0,05$. Oleh karena nilai $\mathrm{P} 0,006<0,05$ maka dapat diartikan bahwa pengaruh kemampuan tenaga penjualan terhadap kinerja pemasaran adalah positif sehingga semakin tinggi kemampuan tenaga penjualan maka akan semakin tinggi pula kinerja pemasaran.

\section{Pengujian Hipotesis 2}

Berdasarkan pada tabel 4 diketahui bahwa variabel strategi pelayanan outlet memiliki nilai probabilitas $0,030<0,05$. Oleh Karena nilai $\mathrm{P} 0,030<0,05$ maka dapat diartikan bahwa pengaruh strategi pelayanan outlet terhadap kinerja pemasaran adalah positif sehingga semakin tinggi strategi pelayanan outlet maka akan semakin tinggi pula kinerja pemasaran. 


\section{Pengujian Hipotesis 3}

Berdasarkan pada tabel 4 diketahui bahwa variabel hubungan dengan outlet memiliki nilai probabilitas $0,006<$ 0,05 . Oleh karena nilai $\mathrm{P} 0,006<$ 0,05 maka dapat diartikan bahwa pengaruh hubungan dengan outlet terhadap kinerja pemasaran adalah positif sehingga semakin tinggi hubungan dengan outlet maka akan semakin tinggi pula kinerja pemasaran.

\section{KESIMPULAN DAN SARAN}

\section{A. Kesimpulaan}

1. Nilaiprobabilitas pengaruh antara kemampuan tenaga penjualan terhadap kinerja pemasaran memiliki nilai $\mathrm{P} 0,006<0,05$, maka hipotesis 1 dalam penelitian ini diterima.

2. Nilaiprobabilitas pengaruh antara strategi pelayanan outlet terhadap kinerja pemasaran memiliki nilai P $0,030<0,05$, maka hipotesis 2 penelitian ini diterima.

3. Nilaiprobabilitas pengaruh antara hubungan dengan outlet terhadap kinerja pemasaran memiliki nilai P $0,006<0,05$, maka hipotesis 3 penelitian ini diterima.

\section{B. Saran}

1. Manajemen perusahaan sudah seharusnya untuk memperbaiki tenaga penjual dengan cara menambahkan pelatihan khusus kepada tenaga penjualnya guna meningkatkan skill dalam hal negoisasi kepada outlet rekanan.

2. Guna meningkatkan pelayanan yang berkualitas terhadap outlet diharapkan kepada perusahaan/distributor agar dapat mengirim barang tepat waktu kepada outlet, setiap pesanan yang diminta outlet kepada distributor sudah seharusnya dipenuhi terutama pada bukubuku yang Best Seller.

3. Hubungan yang baik dengan outlet dapat tercipta jika terjadinya komunikasi yang baik antara pihak distributor yang diwakili oleh tenaga penjual dengan pihak outlet. Maka diharapkan kepada tenaga penjual untuk selalu rutin melakukan kunjungan ke outlet dan memberikan informasi-informasi mengenai ketersediaan stok buku Best Seller, buku STO, dan program promosi kepada pihak outlet.

\section{DAFTAR PUSTAKA}

Albrecht. K. And R. Zembe.1985. Service Amerika! Doing Business in the New. Economy. Homewood III: Dow Jones-Irwin.

Arif, M Idris. 2004, Analisis Kinerja Distribusi Selling-In Untuk Meningkatkan Kinerja Pemasaran, Jurnal Sains Pemasaran Indonesia, Volume III, Nomor 1, p. 55-70

Challagalla, N. Goutham \& Shervani, A. Tasadduq. 2006. Dimensional and type of Supervisory Control: Effect on Sallesperson Performance and Satisfaction. Journal of Marketing, Vol. 60. January

Day, George S., 2000, Managing Market Relationship, Journal of the Academy of Marketing Science, Vol. 28, No. 1, p. 24-30. Ferdinand, Augusty, 2004, Strategic Selling-In Management, Research Paper Series 3, Program MM UNDIP, Semarang. 
Ferdinand, Augusty. 2006. Metode Penelitian Manajemen. Badan Penerbit Universitas Diponegoro, Semarang.

Gao, Yui, 2010, Measuring Marketing Performance: a Review and a Framework. The Marketing. Review.

Ghozali, Imam 2017, Model Persamaan Struktural Konsep Dan Aplikasi Dengan Program Amos 24 Update Bayseian SEM Edisi 7, Penerbit Universitas Diponegoro, Semarang.

Pasaribu, V. L. D. P. D. (2018). PENGARUH BIAYA PROMOSI TERHADAP PENINGKATAN PENJUALAN KARTU FLEXI PT. TELEKOMUNIKASI SELULER (TELKOMSEL) JAKARTA (Studi kasus Produk Kartu Flexi Pt. Telkomsel. Jakarta Selatan). Jurnal Pemasaran Kompetitif, 1(2).

Pasaribu, V. L. D., \& Prayoga, M. Y. S. (2019). PENGARUH KUALITAS PRODUK BAJU BATIK HEM TERHADAP KEPUASAN PELANGGAN PADA HOME INDUSTRI BATIK SAHARA INDAH. Jurnal Pemasaran Kompetitif, 2(2), 77-83.

PASARIBU, V. L. D. (2017). ANALISIS PENGARUH PROMOSI, KUALITAS PRODUK DAN DESAIN KEMASAN TERHADAP PERSEPSI MEREK YANG BERDAMPAK KEPADA KEPUTUSAN PEMBELIAN HAND AND BODY LOTION MEREK VASELINE (Studi Kasus TIP TOP Ciputat, Tangerang Selatan). INOVASI, 4(2).

Pasaribu, V. L. D., \& Jaenanto, J. (2020, January). PENGARUH KUALITAS PELAYANAN TERHADAP TINGKAT KEPUASAN PENYEWA RUANG KANTOR DI PT ISMAWA TRIMITRA GEDUNG GRAHA
ISKANDARSYAH PERIODE 2018 JAKARTA SELATAN. In PROCEEDINGS (Vol. 2, No. 1). Qurbani, D., \& Pasaribu, V. L. D. (2019). PENGARUH BRAND IMAGE DAN BRAND TRUST TERHADAP BRAND LOYALTY NASABAH PRUDENTIAL SYARIAH PADA PT. FUTURISTIK ARTHA GEMILANG (Studi kasus di kantor cabang agensi Prudential Syariah PT. Futuristik Artha Gemilang Jakarta Selatan). Jurnal Pemasaran Kompetitif, 2(3), 121-135.

Sampurno. 2010. Manajemen Stratejik: Menciptakan Keunggulan Bersaing Yang Berkelanjutan. Gadjah Mada University Press. Yogyakarta.

Sugiyono, 2015, Metode Penelitian Manajemen, CV Alvabeta, Bandung.

Sunaryo, Bambang B, 2002, Dinamika Strategi Pelayanan Outlet dan Kinerja Pemasaran, Journal Sains Pemasaran Indonesia, Vol. 1, No. 1, Mei, p.41-56.

Wiryawan, Isidorus Edo, 2008, Analisis Faktor-Faktor Yang Menentukan Kinerja Selling-In DanPengaruhnya Terhadap Kinerja Pemasaran (Studi Kasus pada CV. Cahaya Mulia LestariSemarang), Tesis, Program Magister Manajemen Pascasarjana, Universitas Diponegoro, Semarang. 